\title{
Identification and Partial Characterization of Mesenchyme-Derived Growth Factor That Stimulates Proliferation and Inhibits Functional Differentiation of Mouse Mammary Epithelium in Culture
}

\author{
Michiyoshi TAGA $^{1)}$, Teruyo SAKAKURA ${ }^{2)}$ And TAKami OKA ${ }^{3)}$ \\ 1) Dept. of Obstetrics and Gynecology, Yokohama City \\ Univ. School of Medicine, Yokohama, Japan. \\ 2) RIKEN Tsukuba Life Science Center, The Institute \\ of Physical and Chemical Research, Japan. \\ 3) NIDDK, National Institutes of Health, Bethesda, U.S.A.
}

\begin{abstract}
The effect of mesenchyme on both proliferation and differentiation of mammary epithelial cells was investigated in a primary cell culture system. Mammary cells cultured on collagen gel for 4 days produced casein in response to the synergistic action of insulin, cortisol, and prolactin. When mammary epithelial cells were co-cultured with fibroblasts derived from three different kinds of fetal mesenchymal tissues, casein production was suppressed. The addition of conditioned media obtained from cultures of these mesenchymal cells stimualted DNA synthesis and reduced casein synthesis in a dose-dependent fashion in the cultured mammary cells. Although such biological actions are similar to those of epidermal growth factor (EGF), the capability to compete with EGF for EGF receptor was not found in this conditioned medium. Sephadex G-200 column chromatography revealed that molecular weight of the peak which has these biological activities was around 100,000. These results indicate that fetal mesenchymal cells secrete a substance(s) which has a stimulatory effect on proliferation and an inhibitory effect on differentiation of mammary epithelial cells.
\end{abstract}

Among a variety of cell-to-cell interactions, epithelial-mesenchymal interaction is most important in determining the growth and differentiation of many tissues including epithelial cells. During embryogenesis, the interactions between epithelium and mesenchyme are essential for organogenesis and cytodifferentiation (Fleischmajer and Billingham, 1968; Grobstein, 1967 ; Sawyer and Fallon, 1983). Even in adult, the

Received March 7, 1989 mesenchymal tissue of embryo affects the morphogenesis and cytodifferentiation of the epithelial cells (Cunha et al., 1983; Neubauer et al., 1983; Sakakura et al., 1979). With respect to the mechanism of the interactions, two main possible processes have been considered. One is the diffusion of chemical signals (e.g. so-called inducers, hormones and growth factors) either from adjacent cells or from other parts of the organism (Massague, 1987), and the other is related to the changes in the composition, 
structure, and function of the extracellular matrix substances (Bernfield and Banerjee, 1978 ; Hay, 1977 ; Slavkin et al., 1981). However, the precise mechanism responsible for such biological actions is still unknown.

In the last decade, much has been learned about the role of steroid hormones in the embryonic development and expression of functional activity of various organs. For example, in sex differentiation of sex glands, such as mouse mammary gland (Drews and Drews, 1977 ; Durnberger et al., 1977) and urogenital organs (Cunha and Lung. 1979 ; Lasnitzki and Mizuno, 1980), the masculin morphogenesis is triggered by androgen produced by the fetal testes. According to the tissue recombination experiments using androgen receptor negative $\mathrm{Tfm} / \mathrm{Y}$ mutant mice, such androgen-induced sex differentiation is mediated by the androgen receptors in the mesenchyme. Smith and his colleague (1983) have demonstrated that glucocorticoid induction of surfactant in lung alveolar type II cell and tyrosine aminotransferase in hepatocyte is stimulated by fibroblast pneumonocyte factor and fibroblast hepatocyte factor (Dow et al., 1983), which are produced specifically by embryonic lung and liver fibroblasts, respectively.

Besides hormones, recently several kinds of growth factors have been identified as growth-promoting humoral factors, which are required for cell growth and differentiation. However, there is little evidence for the involvement of growth factors in the control of mechanism of epithelial-mesenchymal interaction.

Previously we reported a primary mouse mammary epithelial cell culture system in which the mammary cells proliferate and differentiate in response to the synergistic action of insulin, cortisol, and prolactin (Taketani and Oka, 1983 a). By using this culture system, we have demonstrated that epidermal growth factor (EGF) and 12-0tetra-decanoylphorbol 13-acetate (TPA) stimulate cell growth and inhibit milk protein synthesis in mammary epithelium (Taketani and Oka, 1983 b, c.).

In order to assess the possible involvement of mesenchyme in the regulation of epithelial function, we investigated the effects of mesenchyme on both cell proliferation and differentiation of epithelium in this system. In this paper, we will report the identification of a new growth factor(s) which is produced and secreted by mesenchyme and regulates the mammary epithelial cell function, and also report the partial characterization of this substance(s).

\section{Materials and Methods}

\section{Materials}

Materials were obtained as follows: $\mathrm{C} 3 \mathrm{H} / \mathrm{HeN}$ mice from the Animal Breeding Facility, National Institutes of Health; $\mathrm{L}^{3}{ }^{3} \mathrm{H}$ amino acid mixture $(1 \mathrm{mCi} / \mathrm{ml})$ from $\mathrm{ICN}$; methyl ${ }^{3} \mathrm{H}$ thymidine $(77$ $\mathrm{Ci} / \mathrm{mmol}$ ) and ${ }^{125} \mathrm{I}$-epidermal growth factor (EGF) from New England Nuclear; Medium 199 (Hanks' salt), fetal bovine serum and trypsin from GIBCO; mouse EGF (receptor grade and culture grade) from Collaborative Research; trypsin from Pierce Chemical Co.; trypsin inhibitor (soybean) from Calbiochem ; crystalline porcine zinc insulin from Lilly Research Laboratories; bovine prolactin (Lot No. B5) from the Hormone Distribution Program, NIADDK, NIH ; and Sephadex G-200 from Pharmacia.

\section{Primary Culture of Mammary Epithelial Cells}

The primary culture of mammary epithelial cells of lactating mice, 3 to 5 days post-partum, was performed as described previously (Taketani and Oka, 1983 a). Cell culture was carried out for 4 days with a daily medium change. Cells were cultured with Medium 199 supplemented with $10 \%$ fetal bovine serum for the first $24 \mathrm{~h}$ and with Medium 199 containing 5\% fetal bovine serum, insulin $(5 \mu \mathrm{g} / \mathrm{ml})$, cortisol $(3 \mu \mathrm{M})$ :and prolactin $(5 \mu \mathrm{g} / \mathrm{ml})$, with or without conditioned media obtained from cultures of mesenchymal cells, for the last 3 days. 


\section{Primary Culture of Embryonic Mesenchymal Cells}

Mouse embryonic tissues were obtained from three different sources: the salivary gland, the mammary gland and the skin, and placed in Medium 199 containing 10\% fetal bovine serum. The capsular mesenchyme of the salivary rudiments taken from 13-14 day fetuses was removed mechanically with cataract knives. The fat pad precursor tissues were removed from the mammary gland of 17 day female fetuses by the dissection technique described before (Sakakura et al., 1982). Skin without prospective mammary fatty stroma was excised from 13-15 day fetuses. Separation of dermis and epidermis was achieved by a slightly modified trypsin digestion technique (Sakakura et al., 1976). Skin was incubated in $2.5 \%$ trypsin for $40-60 \mathrm{~min}$ at room temperature. The mesenchymal components were dissected from the epithelium and were then placed in Medium 199 containing 50\% fetal bovine serum for $2 \mathrm{~h}$ for the trypsin inactivation. Each mesenchymal tissue was transferred to a tissue culture flask. Culture was continued with Medium 199 containing $10 \%$ fetal bovine serum at $37^{\circ} \mathrm{C}$ in humidified air with $5 \% \mathrm{CO}_{2}$ with periodical medium changes. The conditioned media were collected and kept frozen until assay for their biological activities.

\section{Co-culture of Mammary Epithelial Cells with Embryonic Mesenchymal Cells}

Three different kinds of mesenchymal tissues were obtained from 14 day mouse embryos by the procedures described above. Cells of each mesenchyme were prepared by trypsin treatment and placed onto collagen gel-coated Falcon plastic tissue culture plates; salivary mesenchyme at a density of $1.7 \times 10^{5} /$ dish, mammary mesenchyme $1 \times 10^{5} / \mathrm{dish}$, and skin mesenchyme $1 \times$ $10^{5} /$ dish. After they were cultured with Medium 199 containing $10 \%$ fetal bovine serum for 2 days, mammary epithelial cells from lactating mice were added on the layer of mesenchymal cells at a density of $1 \times 10^{5} / \mathrm{dish}$ according to the procedures as described in primary culture of mammary epithelial cells. Co-culture was continued in the presence of $10 \%$ fetal bovine serum for one day and $5 \%$ fetal bovine serum, insulin $(5 \mu \mathrm{g} / \mathrm{ml})$, cortisol $(3 \mu \mathrm{M})$ and prolactin $(5 \mu \mathrm{g} / \mathrm{ml})$ for $43 \mathrm{~h}$. Culture media were changed and culture was continued for another $43 \mathrm{~h}$ in the same fresh media.

\section{DNA Synthesis}

The extent of DNA synthesis was determined by allowing cells to incorporate ${ }^{3} \mathrm{H}$-thymidine $(0.5 \mu \mathrm{Ci} / \mathrm{ml})$ into trichloroacetic acid-insoluble materials for $24 \mathrm{~h}$ (Taketani and Oka, $1983 \mathrm{a}$ ).

\section{Casein Synthesis}

The extent of casein synthesis was determined by allowing cells to incorporate $\mathrm{L}^{3} \mathrm{H}$ amino acid mixture $(10 \mu \mathrm{Ci} / \mathrm{m} 1)$ for $24 \mathrm{~h}$. The amounts of casein released into media were measured by an indirect immunoprecipitation method (Ono and Oka, 1980).

\section{Column Chromatography}

Two $\mathrm{ml}$ of conditioned medium obtained from culture of mesenchymal cells of fetal skin was applied to a Sephadex G-200 column, 1.5× $50 \mathrm{~cm}$, and eluted in 2-m1 fractions with $1 \mathrm{M}$ acetic acid at a flow rate of $5 \mathrm{ml} / \mathrm{h}$ at $4^{\circ} \mathrm{C}$. After absorbance was measured at $280 \mathrm{~nm}$ in a Gilford Spectrometer, each fraction was lyophilized and dissolved in Medium 199 containing $5 \%$ fetal bovine serum, insulin $(5 \mu \mathrm{g} / \mathrm{ml})$, cortisol $(3 \mu \mathrm{M})$ and prolactin $(5 \mu \mathrm{g} / \mathrm{ml})$. The solution was added to the primary mammary epithelial cell culture in order to test its biological activities.

\section{${ }^{125}$ I-EGF Binding Assay}

EGF binding assay was carried out slightly modified as described previously (Taketani and Oka, 1983 b). The incubation was performed at room temperature for $2 \mathrm{~h}$ with constant shaking. Each tube contained $2 \times 10^{6}$ mammary epithelial cells suspended in $250 \mu 1$ of Medium 199 containing $0.25 \%$ of bovine serum albumin, $250 \mu 1$ of diluted conditioned media $(0-100 \%)$ obtained from culture of fetal skin mesenchyme or $250 \mu 1$ of EGF $(0-100 \mathrm{ng} / \mathrm{ml})$ and $100 \mu 1$ of ${ }^{125}$ I-EGF (approximately $1.2 \times 10^{6} \mathrm{cpm}$ ) with or without $10 \mu \mathrm{l}$ of unlabeled EGF ( $1 \mu \mathrm{g})$. Specific ${ }^{125}$ I-EGF binding was measured by subtracting the amount of radioactivity bound nonspecifically in the presence of exess unlabeled hormone. These assays were conducted in triplicate.

\section{Results}

In order to examine the effects of mesenchymal cells on casein production by 
mammary epithelial cells, three different kinds of embryonic mesenchymal cells were co-cultured with mammary epithelial cells for 4 days. Fig. 1 shows the amounts of casein which were produced in the last $43 \mathrm{~h}$ of these co-cultures. The presence of embryonic mesenchymal cells in direct contact with mammary epithelial cells markedly reduced the amounts of casein released into culture medium. All kinds of embryonic mesenchymal cells, i.e., those from salivary gland, mammary gland and skin, had this inhibitory action on casein production regardless of their sources. Among these three mesenchymal tissues, mammary mesenchyme had the strongest inhibitory effect on milk protein synthesis.

The effects of conditioned media obtained from three different kinds of mesenchymal cell cultures on DNA synthesis and casein production in mammary epithelial cells are shown in Fig. 2. The addition of conditioned media into culture medium of mammary epithelial cell culture enhanced DNA synthesis 5-8 fold (I) and reduced casein synthesis by about a half (II). A1-

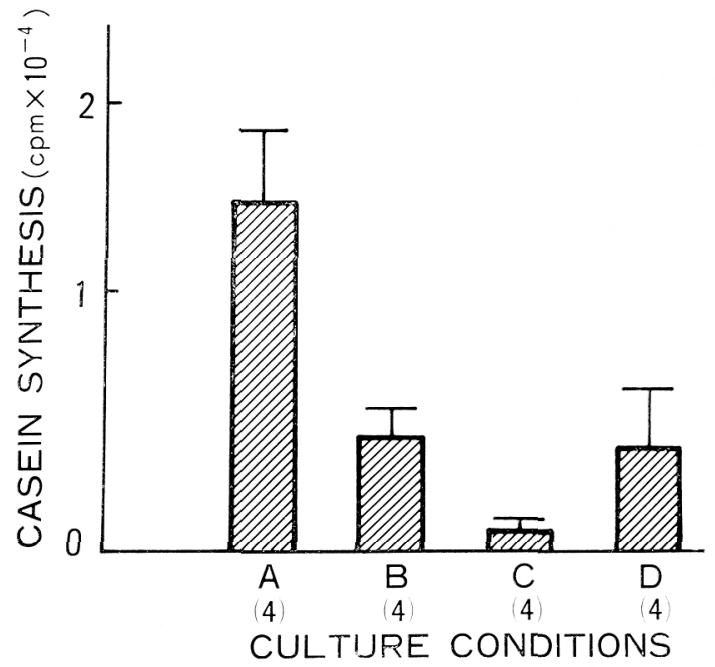

Fig. 1. Inhibition of casein synthesis in mammary epithelial cells by embryonic mesenchymal cells. Culture was performed as described in Materials and Methods under the following culture conditions: mammary epithelial cells alone (A), co-culture of mammary epithelial cells with salivary mesenchyme (B), co-culture with mammary mesenchyme (C), and co-culture with skin mesenchyme (D). The amounts of casein produced are expressed as $\mathrm{cpm}$ per $1 \times 10^{5}$ cells of each mesenchyme.
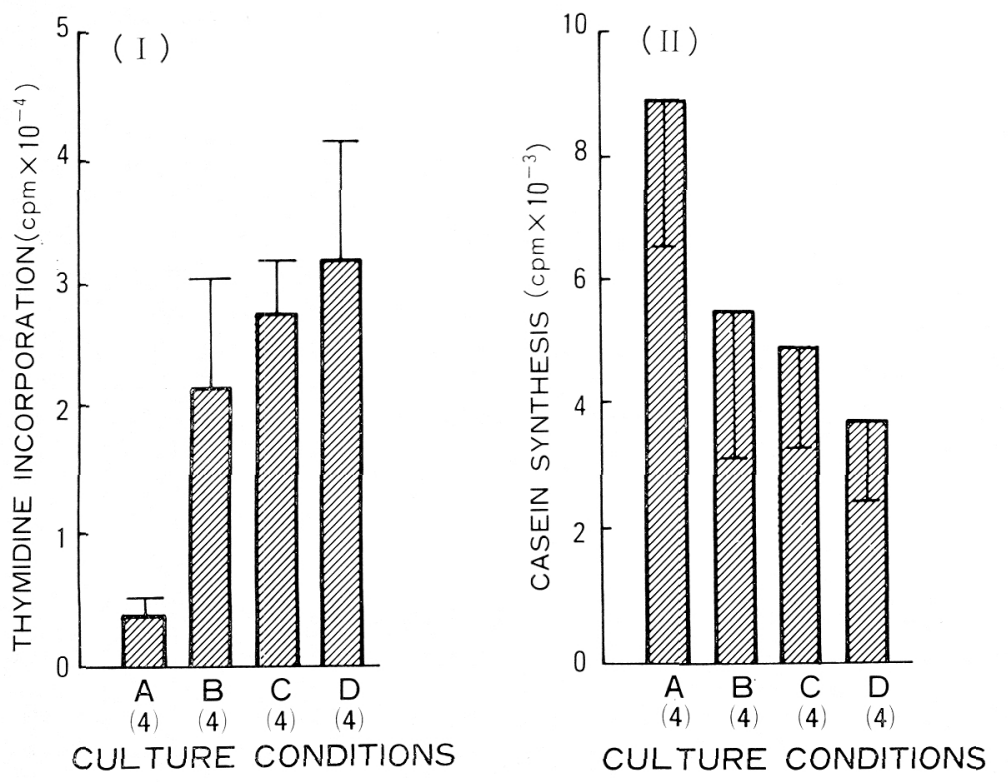

Fig. 2. Effects of conditioned media from embryonic mesenchymal cell cultures on DNA synthesis (I) and casein synthesis (II) in mammary epithelial cells. Mammary cells were cultured in medium containing 5\% fetal bovine serum, insulin, cortisol, and prolactin (A) or in medium containing these agents and conditioned medium derived from salivary mesenchyma1 culture (B), mammary mesenchyme culture (C), or skin mesenchyme culture (D). ${ }^{3} \mathrm{H}$-amino acid mixture or ${ }^{3} \mathrm{H}$-thymidine was added into the medium in the final $24 \mathrm{~h}$ of culture. 
though the conditioned medium obtained from culture of fetal skin mesenchyme had the strongest activity, it was difficult to quantitatively compare the activities of the three different kinds of embryonic mesenchymal cells because the conditioned media were not always obtained under the same culture conditions. Fig. 3 shows a clear dose-dependent relationship between the amount of conditioned media obtained from culture of fetal skin mesenchyme and the stimulation of DNA synthesis (I) as well as the inhibition of casein synthesis (II).

The results of experiments on the stability of this substance are summarized in Table 1. The treatment of conditioned medium obtained from culture of fetal skin mesenchyme with various doses of trypsin
( I )

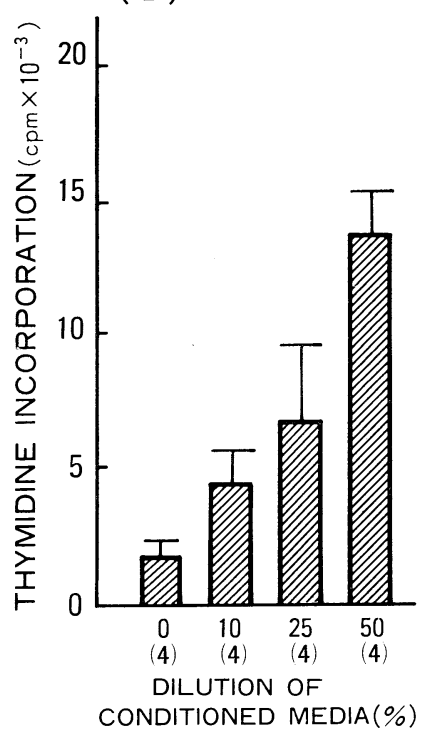

( II )

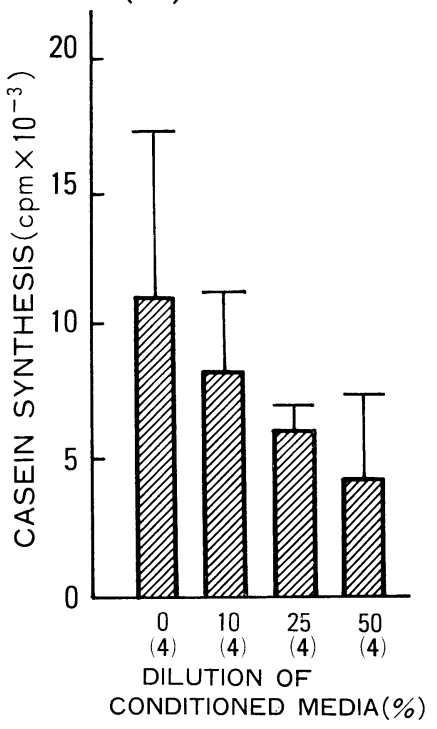

Fig. 3. Effect of different amounts of conditioned medium from culture of fetal skin mesenchyme on DNA synthesis (I) and casein synthesis (II) in mammary epithelial cells. Mammary cells were cultured in medium containing $5 \%$ fetal bovine serum, insulin, cortisol, prolactin, and the amount of conditioned medium indicated. ${ }^{3} \mathrm{H}$-amino acid mixture or ${ }^{3} \mathrm{H}$-thymidine was added into the medium in the final $24 \mathrm{~h}$ of culture.

Table 1. Effects of treatment of conditioned medium from fetal skin mesenchyme with trypsin or heating on DNA synthesis in cultured mammary epithelial cells. Mammary cells were cultured in medium containing fetal bovine serum, insulin (I), cortisol (F), and prolactin (P) with or without conditioned medium (C. M.). Conditioned media were treated with trypsin at concentrations indicated or with heating at $60^{\circ} \mathrm{C}$ for $30 \mathrm{~min}$.

\begin{tabular}{lrr}
\hline \multicolumn{1}{c}{ Culture Conditions } & \multicolumn{2}{c}{$\begin{array}{c}\text { Thymidine Incorporation } \\
\text { cpm/dish/24 h }\end{array}$} \\
\hline IFP & $(4)$ & $4098 \pm 251$ \\
IFP + C. M. & $(4)$ & $43514 \pm 1652$ \\
IFP + C. M. treated with $0.1 \mathrm{mg} / \mathrm{ml}$ of trypsin & $(4)$ & $33542 \pm 683$ \\
IFP + C. M. treated with $0.5 \mathrm{mg} / \mathrm{ml}$ of trypsin & $(4)$ & $28129 \pm 779$ \\
IFP + C. M. treated with $1.0 \mathrm{mg} / \mathrm{ml}$ of trypsin & $(4)$ & $13969 \pm 302$ \\
\hline IFP & $(4)$ & $3805 \pm 311$ \\
IFP + C. M. & $(4)$ & $45124 \pm 801$ \\
IFP + C. M. heated at $60^{\circ} \mathrm{C}$ for $30 \mathrm{~min}$ & $(4)$ & $29770 \pm 726$ \\
\hline
\end{tabular}




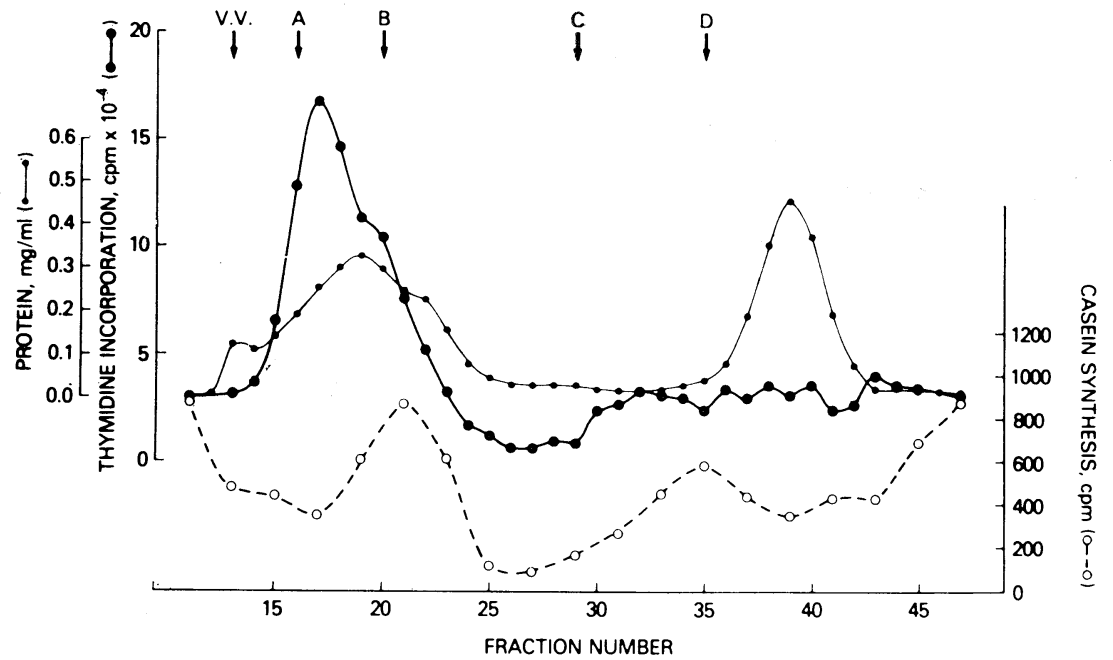

Fig. 4. Sephadex G-200 column chromatography of conditioned medium from a culture of fetal skin mesenchyme. Each fraction was tested for DNA synthesis casein synthesis (O_. - ) and absorbance at $280 \mathrm{~nm}\left(\cdot \bullet_{-}\right)$. The column was calibrated by using the following molecular weight standards: aldolase (A), 158,000 MW ; bovine serum albumin (B), 68,000 MW ; cytochrome C (C), 12,500 MW; and insulin (D), $6,000 \mathrm{MW}$. Blue dextran was used to identify the void volume of this column (V.V.).

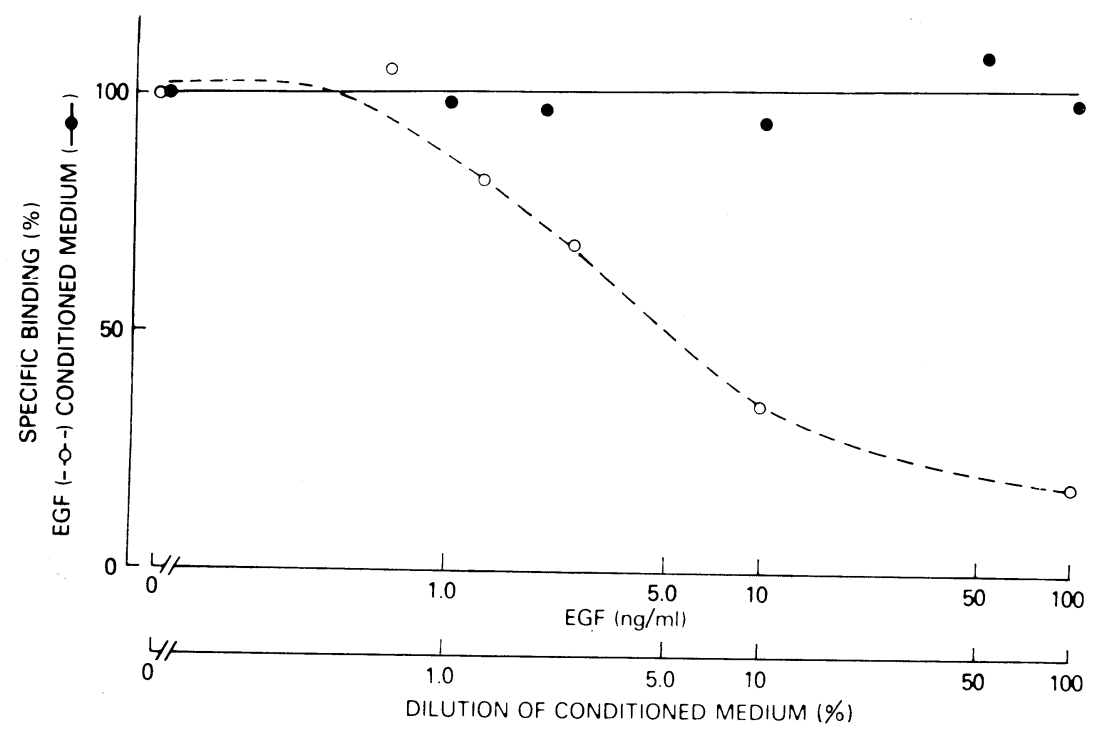

Fig. 5. Effect of conditioned medium from culture of fetal skin mesenchyme on the amount of specific ${ }^{125}$ I-EGF binding of mammary epithelial cells. Mammary cells were incubated in medium containing $0.25 \%$ bovine serum albumin and ${ }^{125}$ I-EGF (approximately $1.2 \times 10^{5} \mathrm{cpm}$ per tube) with diluted conditioned media or EGF standards. 
decreased its stimulatory activity on DNA synthesis in a dose-dependent fashion. The heating of conditioned medium from culture of fetal skin mesenchyme at $60^{\circ} \mathrm{C}$ for 30 min reduced its activity by $34 \%$.

Fig. 4 shows the elution profile of Sephadex G-200 column chromatography of conditioned medium obtained from a culture of fetal skin mesenchymal cells. The peak having the activity of stimulating DNA synthesis was observed in fractions around 17 indicating that its molecular weight was approximately 100,000. In these fractions, the activity of casein synthesis was suppressed. The slightly inhibitory effect on DNA synthesis was detected in fractions around 27 , in which the production of casein was also inhibited.

The addition of all diluted conditioned media obtained from a culture of fetal skin mesenchymal cells did not change ${ }^{125}$ I-EGF specific binding in mammary epithelial cells in spite of their strong ability to enhance DNA synthesis and to inhibit casein production, indicating that this substance cannot compete with EGF for EGF receptor (Fig. $5)$.

\section{Discussion}

The present study has shown that fetal mesenchymal cells secrete a substance(s) which can enhance DNA synthesis and inhibit casein production in mouse mammary epithelial cells in culture. These effects of this substance are very similar to those of EGF in mammary epithelial cells in the same culture system, which was previously reported in our laboratory. However, it appears that this substance is quite different from EGF based on its molecular weight. Furthermore, the addition of anti-EGF antibody did not abolish these biological actions of this substance and it did not compete with EGF for EGF receptor in mammary epithelial cells. Sephadex G-200 column chromatography revealed that the peak which has activity capable of inducing DNA synthesis and reducing casein synthesis has a molecular weight of approximately 100,000 .

Recently, EGF-like transforming growth factors (TGFs) have been identified in mouse and rat embryos (Heine et al., 1987 ; Matrisian et al., 1982; Twardzik et al., 1982). Twardzik et al., (1982) reported that growth factors, which stimulate anchorage-independent growth of normal mouse and rat fibroblasts and have the ability to compete with ${ }^{125}$ I-labeled EGF for receptor binding, can be isolated from 12-to 13-day-old normal mouse embryos of various strains. Although this growth factor identified in this study was derived from fetal mesenchymal tissue, it is different from that which Twardzik et al. reported because it does not possess the activity to bind to EGF receptor and the molecular weights of these two growth factors are quite different. The molecular weight of this growth factor is greater than those of TGFs isolated so far which have a molecular weight of 6000-25000 (Roberts et al., 1983).

This growth factor is sensitive to trypsin, which is common with TGF reported in rat fetus (Matrisian, 1982), but some properties such as lack of heat stability are different from those of TGFs.

Our cell culture system for mammary epithelial cells offers a sensitive assay for DNA synthesis as well as casein production. By using this system, we could demonstrate that this growth factor strongly inhibits cell differentiation. This finding is very important since there has been little study on the effects of TGFs on the functional aspect of cell differentiation.

There are several mechanism for regulating epithelial-mesenchymal interaction (Cunha et al., 1983; Fleischmajer and Billingham, 1968; Grobstein, 1967; Neubauer et al., 1983; Sakakura et al., 1979; Sawyer and Fallon, 1983). In mammary gland 
development, the inductive interactions between epithelium and mesenchyme are essential for normal morphogenesis in the fetal stage (Kratochwil, 1969; Sakakura, 1987) and also in adult life (Sakakura et al., 1979). The dependency of mammary epithelium in its morphology on the mesenchymal stroma is shown. Levine and Stockdale (1984) reported that the interaction of mammary epithelium with adipocytes resulted in a marked increase in the proliferation of mammary epithelium and that extra cellular components may mediate this effect. The following question then arises: What role does the fetal mesenchyme-derived growth factor play in mammary gland development? Our present study raised the possibility that this growth factor controls the cell function of epithelium by exerting a stimulatory effect on cell proliferation and an inhibitory effect on cell differentiation. However, mammary epithelium, which is quite different from other epithelia, proliferates after puberty with each ovarian cycle and further proliferates during each successive pregnancy. Is this growth factor released from fetuses, and does it promote the epithelial cell proliferation of the mother mammary glands through the placenta? To answer this question, further studies are necessary to identify this humoral factor in the serum of the pregnant mouse and to investigate the tissue and function specificity by changing the combinations of epithelial and mesenchymal cells. The present studies antecedently indicate that the growth factor released from fetal mesenchyme seems to have these activities regardless of the origin of tissue: mesenchymal cells from salivary gland and skin also have a biological action on mammary epithelium as mammary mesenchyme does, although this action is not as strong as that of mammary mesenchyme. This suggests the presence of two different types of growth factors in embryonic mesenchyme; one is tissue specific and the other is a tissue non-specific growth factor.
The analysis by column chromatography revealed that conditioned medium from fetal mesenchymal cell culture contained not only stimulatory substance but also inhibitory substance in DNA synthesis, depending on the difference in molecular weight. The physiological role of this inhibitory action of mesenchyme on epithelial proliferation is unknown.

Many newly discovered peptide growth factors are produced and released in the immediate vicinity of their site of action and such a control of cell growth and differentiation is considered to be a primitive regulatory mechanism (Bradshaw and Sporn, 1983). The growth factor identified in our study may exert its effect by this mechanism. This regulatory system probably is fundamentally important for epithelialmesenchymal interaction as well as for the fetal development.

\section{References}

Bernfield, M. R. and S. D. Banerjee (1978). In Proceedings, First International Symposium on the Biology and Chemistry of Basement Membranes. Philadelphia. (N. A. Kefalides ed.), Academic Press, New York. pp. 137-148. Bradshaw, R. A. and M. B. Sporn (1983). Polypeptide growth factors and the regulation of cell growth and differentiation. Fed. Proc. $42,2590-2591$.

Cunha, G. R. and B. Lung (1979). The importance of stroma in morphogenesis and functional activity of urogenital epithelium. In Vitro 15, 50-71.

Cunha, G. R., H. Fulli., B. L. Neubauer, L. Sawyer, J. M. Shannon and B. A. Reese (1983). Epithelial-mesenchymal interactions in prostatic development. I Morphological observation of prostatic induction by urogenital sinus mesenchyme in epithelium of the adult rodent urinary bladder. J. Cell Biol. 96, 1662-1670.

Dow, K. E., K. Sabry and B. T. Smith (1983). Evidence for epithelial-mesenchymal interactions mediating glucocorticoid effects in developing chick liver. Cell Tissue Res. 231, 
83-91.

Drews, U. and U. Drews (1977). Regression of mouse mammary gland anlagen in recombinants of $\mathrm{Tfm}$ and wild-type tissues: testosterone acts via the mesenchyme. Cell 10, 401-404.

Durnberger, H., B. Heuberger, P. Schwartz, G. Wasner and K. Kratochwil (1977). Mesenchyme-mediated effect of testosterone on embryonic mammary epithelium. Cancer Res. 38, 4066-4070.

Fleischmajer, R. and R. Billingham (1968). Epithelial-Mesenchymal Interactions. Williams \& Wilkins, Baltimore.

Grobstein, C. (1967). Mechanisms of organogenetic tissue interaction. Natl. Cancer Inst. Monogr. 26, 279-299.

Hay, E. D. (1977). In International Cell Biology 1976-1977 (B. R. Brinkley and K. R. Porter eds.) The Rockfeller University Press, pp. 50-57.

Heine, U. I., E. F. Munoz, K. C. Flanders, L. R. Ellingsworth, H. Y. Lam, N. L. Thompson, A. B. Roberts and M. B. Sporn (1987). Role of transforming growth factor- $\beta$ in the development of the mouse embryo. $J$. Cell Biol. 105, 2861-2876.

Kratochwil, K. (1969). Organ specificity in mesenchymal induction demonstrated in the embryonic development of the mammary gland of the mouse. Develop. Biol. 20, 46-71.

Lasnitzki, I. and T. Mizuno (1980). Prostatic Induction: Interaction of epithelium and mesenchyme from normal wild-type mice and androgen-insensitive mice with testicular feminization. $J$. Endocrinol. 85, 423-428.

Levine, J. F. and F. E. Stockdale (1984). 3T3Ll Adipocytes promotes the growth of mammary epithelium. Exp. Cell Res. 151, 112122.

Massague, J. (1987). The TGF- $\beta$ family of growth and differentiation factors. Cell 49 , 437-438.

Matrisian, L. M., M. Pathak and B. E. Magun (1982). Identification of an epidermal growth factor-related transforming growth factor from rat fetuses. Biochem. Biophy. Res. Commun. 107, 761-769.

Neubauer, B. L., L. W. K. Chung, K. A. McCormic, O. Taguchi, T. C. Thompson and G. R. Cunha (1983). Epithelial-mesenchymal interactions in prostatic development. II Biochemical observations of prostatic induction by urogenital sinus mesenchyme in epithelium of the adult rodent urinary bladder. J. Cell Biol. 96, 1671-1676.

Ono, M. and T. Oka (1980). The differential actions of cortisol on the accumulation of $\alpha$ lactalbumin and casein in midpregnant mouse mammary gland in culture. Cell 19, 473-480.

Roberts, A. B., C. A. Frolik, M. A. Anzano and M. B. Sporn (1983). Transforming growth factors from neoplastic and nonneoplastic tissues. Fed. Proc. 42, 2621-2626.

Sakakura, T., Y. Nishizuka and C. J. Dawe (1976). Mesenchymal-dependent morphogenesis and epithelium-specific cytodifferentiation in mouse mammary gland. Science 194, 14391441 .

Sakakura, T., Y. Sakagami and Y. Nishizuka (1979). Persistence of responsiveness of adult mouse mammary gland to induction by embryonic mesenchyme. Develop. Biol. 72, 201210.

Sakakura, T., Y. Sakagami and Y. Nishizuka (1982). Dual origin of mesenchymal tissues participating in mouse mammary gland embryogenesis. Develop. Biol. 91, 202-207.

Sakakura, T. (1987). The Mammary Gland. (C. Margaret, Neville, and W. D. Charles eds.), Plenum Publishing Corporation pp. 37-66.

Sawyer, R. H. and J. F. Fallon (1983). Epithelial-mesenchymal interactions in development. Praeger Publishers, New York.

Slavkin, H. C., M. Zeichner-David and M. A. Siddiqui (1981). Molecular aspects of tooth morphogenesis and differentiation. Molec. Aspects Med. 4, 125-188.

Smith, B.T. and K. Sabrt(1983). Glucocorticoidthyroid synergism in lung maturation: A mechanism involving epithelial-mesenchymal interaction. Proc. Natl. Acad. Sci. USA 80, 1951-1954.

Taketani, Y. and T. Oka (1983 a). Epidermal growth factor stimulates cell proliferation and inhibits functional differentiation of mouse mammary epithelial cells in culture. Endocrinology 113, 871-877.

Taketani, Y. and T. Oka (1983 b). Biological action of epidermal growth factor and its functional receptors in normal mammary epithelial cells. Proc. Natl. Acad. Sci. USA 80, 2647-2650.

Taketani, Y. and T. Oka $(1983 \mathrm{c})$. Tumor promoter 12-0-tetradecanoylphorbol 13-acetate, like epidermal growth factor, stimulates cell 
proliferation and inhibits differentiation of mouse mammary epithelial cells in culture. Proc. Natl. Acad. Sci. USA 80, 1646-1649. Twardzik, D. R., J. E. Rachalis and G. J.
Todaro (1982). Mouse embryonic transforming growth factors related to those isolated from tumor cells. Cancer Res. 42, 590-593. 